\title{
PENDAFTARAN ANGGOTA MARCHING BAND GEMA SWARA (GSKS) KOTA SUKABUMI BERBASIS WEBSITE
}

\author{
Yusti Farlina' ${ }^{1}$, Desi Susilawati ${ }^{2}$, Denny Pribadi $^{3}$ \\ 1,2,3 Universitas Bina Sarana Infromatika \\ e-mail: 1yusti.yfa@bsi.ac.id, ${ }^{2}$ desi.dlu@bsi.ac.id, ${ }^{3}$ denny.dpi@bsi.ac.id
}

\begin{abstract}
Abstraksi
Seni termasuk kedalam salah satu aspek bagian terpenting untuk melengkapi kehidupan. Dengan adanya seni dalam musik menjadi salah satu tujuan untuk pembentuk kepribadian anak dikarenakan dapat meningkatkan logika, rasa estetis, dan tingkat kreatifitas. Di Kota Sukabumi terbentuk unit-unit Marching band baik berasal dari organisasi masyarakat maupun lingkungan sekolah yang menambah kegiatan ekstrakulikuler untuk siswa-siswanya. Sekarang ini Marching band GSKS telah memperluas penambahan anggota dengan menyertakan masyarakat umum untuk ikut bergabung menjadi anggota. Namun dalam penyampaian informasi unit ini masih menggunakan sistem manual, yaitu proses pendaftaran dan penerapan materi untuk calon anggota yang kurang efisien. Dengan membawa keunggulan internet dalam proses bisnis khususnya kegiatan promosi pendaftaran anggota akan memberikan manfaat bagi perusahaan yang menerapkan aplikasi. Sistem pendaftaran secara online akan memudahkan dalam proses pendataan calon pendaftar. Penelitian ini dibuatkan sebuah aplikasi berbasis website. Dengan adanya website pendaftaran anggota baru pada Marching Band Gema Swara (GSKS) dapat mempermudah dan mempercepat proses pendaftaran.
\end{abstract}

Kata Kunci : Pendaftaran, Anggota

\section{Abstract}

Art is included in one of the most important aspects to complete life. With the existence of art in music is one of the goals for shaping a child's personality because it can improve logic, aesthetic sense, and level of creativity. In the City of Sukabumi, Marching Band units were formed, both from community organizations and the school environment, which added extracurricular activities for their students. Now the GSKS Marching band has expanded the addition of members to include the general public to join as members. However, in the delivery of information, this unit still uses a manual system, namely the registration process and application of material for prospective members who are less efficient. By bringing the advantage of the internet in business processes, especially promotional activities member registration will provide benefits for companies that apply the application. The online registration system will facilitate the data collection process of prospective registrants. In this research, a website-based application. With the new member registration website at the Gara Swara Marching Band (GSKS) can simplify and speed up the registration process.

Keywords: Registration, Members

\section{Pendahuluan}

Teknologi informasi yang berkembang dengan cepat dalam berbagai bidang termasuk kesenian digunakan untuk memberikan informasi mengenai kesenian (Choliviana \& Yulianto, 2013). Seni termasuk kedalam salah satu aspek bagian terpenting untuk melengkapi kehidupan. Kesenian merupakan bagian dari kebudayaan yang berhubungan dengan jiwa dan perasaan manusia (Aulia, Gusrayani, \& Julia, 2017). Dengan adanya seni dalam musik menjadi salah satu tujuan untuk pembentuk kepribadian anak dikarenakan dapat meningkatkan logika, rasa estetis, dan tingkat kreatifitas (Pamungkas, 2014). Marching Band adalah perpaduan musik, baris-berbaris, gerak tari dan irama. Walaupun berbau militer dari segi barisberbaris, namun kebanyakan dari tema pagelarannya sudah menjurus pertunjukan seni (Agusta, Lubis, \& Sudarman, 2016).

Di Kota Sukabumi terbentuk unit-unit Marching band baik berasal dari organisasi masyarakat maupun lingkungan sekolah yang menambah kegiatan ekstrakulikuler untuk siswa-siswanya. Akan tetapi, dari sekian banyak unit, Marching Band Gema Swara Kota Sukabumi (GSKS) lah unit dengan alat 
musik melodi yang digunakan lebih banyak dibandingkan alat musik perkusi. Marching band GSKS ini pertama dibentuk dan dibina langsung oleh KORPRI dan pemerintah daerah Kota Sukabumi, dan anggotanya pun merupakan anggota pilihan yang berasal dari unit-unit marching band yang berada di wilayah Kota Sukabumi. Sekarang ini Marching band GSKS telah memperluas penambahan anggota dengan menyertakan masyarakat umum untuk ikut bergabung menjadi anggota. Namun dalam penyampaian informasi unit ini masih menggunakan sistem manual, yaitu proses pendaftaran dan pemilihan materi yang akan dipilih oleh calon pendaftar seperti materi untuk alat musik brass, drum, sexsopone, dll. Dengan membawa keunggulan internet dalam proses bisnis khususnya kegiatan promosi pendaftaran anggota akan memberikan manfaat bagi perusahaan yang menerapkan aplikasi (Farlina, Hudin, Yulianti, \& Maulana, 2019). Sistem pendaftaran secara online akan memudahkan dalam proses pendataan calon pendaftar (Choliviana \& Yulianto, 2013)

\section{Metode Penelitian}

Metode penelitian dan pengumpulan data yang digunakan dalam penelitian ini, yaitu:

A. Metode Pengembangan Perangkat
Lunak
Metode penelitian dan teknik pada
pengembangan perangkat lunak ini
menggunakan model waterfall yang terbagi menjadi lima tahapan, yaitu:

1. Analisa Kebutuhan Perangkat Lunak Proses ini melibatkan pengumpulan kebutuhan secara insentif yang menspesifikasikan perangkat lunak yang dibutuhkan (Dermawan \& Hartini, 2017). Dalam proses ini dilakukan pengumpulan data dari pihak Marching Band Gema Swara (GSKS) dengan memawancarai narasumber mengenai gambaran umum dalam proses pendaftaran calon anggota marching band yang selama ini berjalan. Dari gambaran tersebut dibuatkan proses sistem, tampilan program, dan perancangan database.

2. Desain

Proses ini memfokuskan terhadap pembuatan desain antarmuka serta prosedur pengkodean untuk diimplementasikan terhadap program yang akan dibuat. Setelah dibuat desain antarmuka baru buatkan program sesuai yang dibutuhkan pengguna (Dermawan \& Hartini, 2017). Dalam tahapan ini dibuatkan tampilan gambaran pembuatan aplikasi dengan rancangan Unified Modeling Language (UML) sebagai alat bantu untuk pemodelan sistem yang meliputi admin dan user.

3. Pembuatan Kode Program

Proses ini menerapkan desain antar muka yang telah dibuat kedalam bahasa pemrograman yang akan menggunakan bahasa PHP untuk pembuatan websitenya (Firmansyah, 2018). Dalam pembutaan kode program menggunakan bahasa pemrograman PHP dan untuk database menggunakan MySql.

4. Pengujian

Proses ini memfokuskan terhadap perangkat lunak yang telah dibat untuk dicek kesalahan dan memastikan semua bagian yang dibuat sudah diuji. Proses ini dilakukan untuk meminimalisir kesalahan dan menghasilkan keluaran yang diinginkan pengguna (Tabrani \& Pudjiarti, 2017). Dalam tahapan ini dilakukan pengujian unit menggunakan black box testing, meliputi pengecekan input dan hasil output agar sesuai harapan.

5. Pendukung dan Pemeliharaan

Dalam proses ini merupakan tahapan dari proses sebelumnya, yang melibatkan proses perbaikan terhadap kesalahan yang tidak ditemukan dalam proses pengecekan sebelumnya. Proses ini juga berfungsi meningkatakan imlementasi unit sistem dan layanan sistem (Sasmito, 2017). Dilakukan pemeliharaan dan upgrade tool system dari program yang dibuat agar aplikasi yang dibuat bisa dikembangkan lagi.

\section{B. Teknik Pengumpulan Data}

1. Wawancara (Interview)

Teknik pengumpulan data dengan cara melakukan komunikasi dengan sumber data melalui tanya jawab dengan pihak-pihak yang terkait dan yang bertanggung jawab di bidang-bidang yang diperlukan agar dapat memberikan informasi secara lengkap dan jelas. Dalam hal inni dilakukan tanya jawab langsung dengan Ketua Marching Band Gema Swara Kota Sukabumi (GSKS).

\section{Pengamatan Langsung (Observasi)}

Dilakukan dengan cara menganalisis dan mengadakan pencatatan secara sistematis mengenai hal-hal yang berkaitan dengan pendaftaran dan pemilihan materi pada Marching Band Gema Swara Kota Sukabumi.

3. Studi Pustaka 
Selain melakukan metode diatas juga dilakukan studi kepustakaan melalui referensi buku-buku perpustakaan dan segala kepustakaan lainnya untuk mendukung proses pendaftaran dan pemilihan materi pada Marching Band Gema Swara Kota Sukabumi (GSKS).

\section{Hasil dan Pembahasan}

\subsection{UML (Unified Model Language)}

Pendaftaran anggota berbasis website ini dirancang dengan memiliki dua hak akses yaitu user dan administrator. Untuk calon anggota sebagai user. Petugas pengguna aplikasi ini sebagai administrator. Berikut spesifikasi kebutuhan dari aplikasi pendaftaran anggota marching band, sebagai berikut:

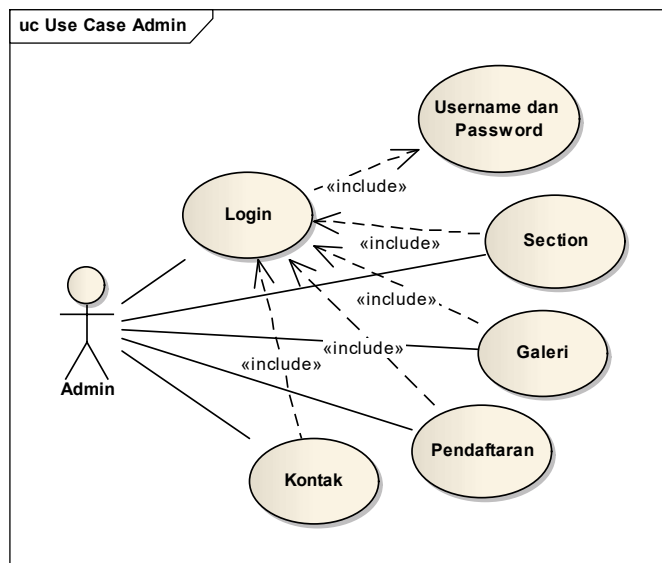

Gambar 1 Use Case Diagram Halaman Admin

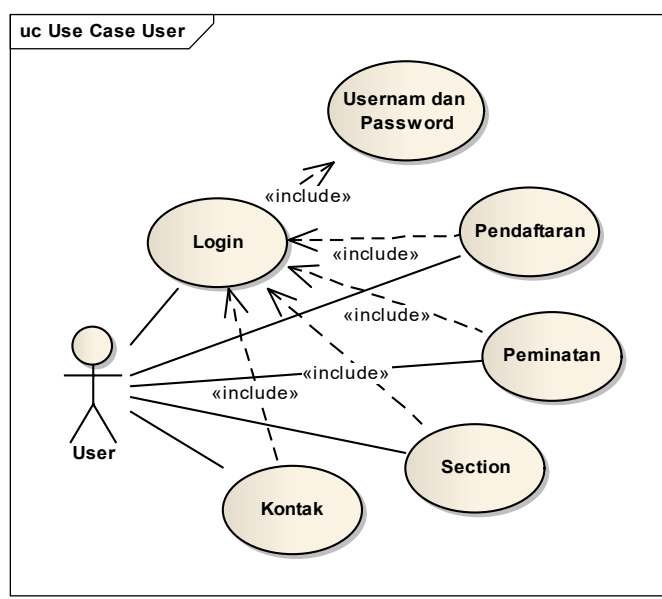

Gambar 2 Use Case Diagram Halaman User

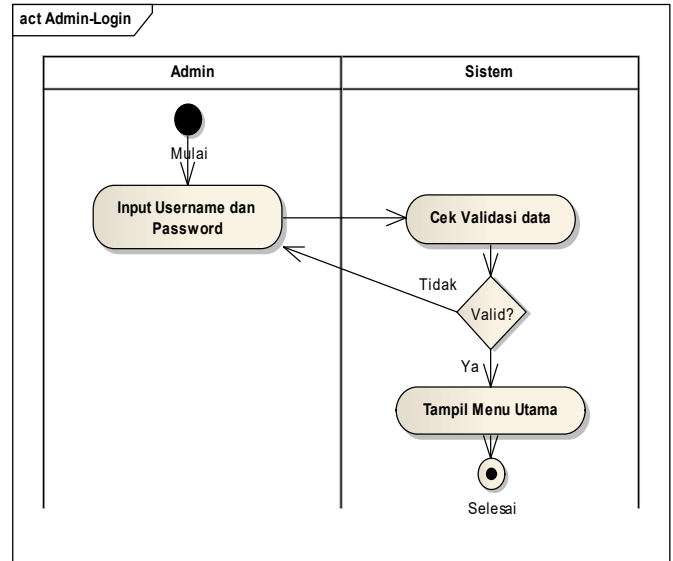

Gambar 3 Activity Diagram Halaman Login Admin

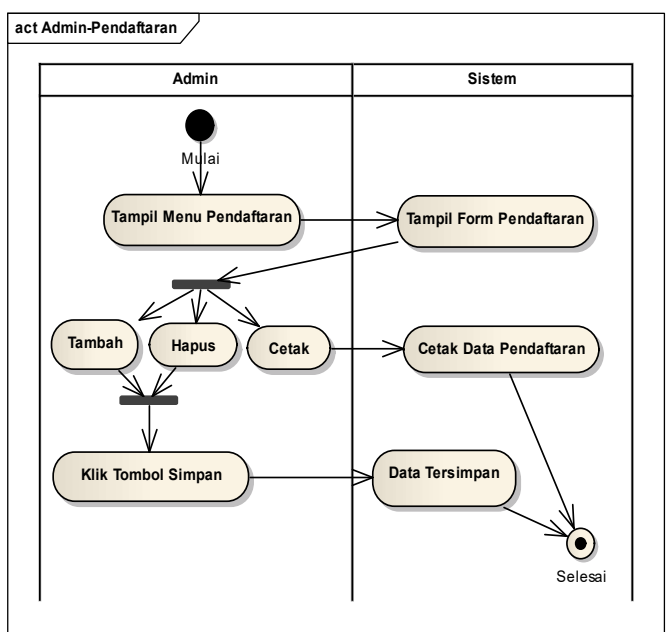

Gambar 4 Activity Diagram Halaman Pendaftaran Admin

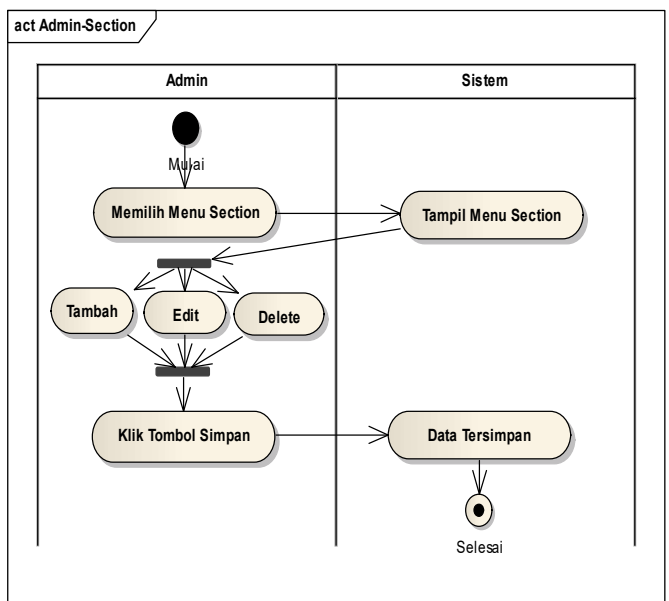

Gambar 5 Activity Diagram Halaman Section Admin 


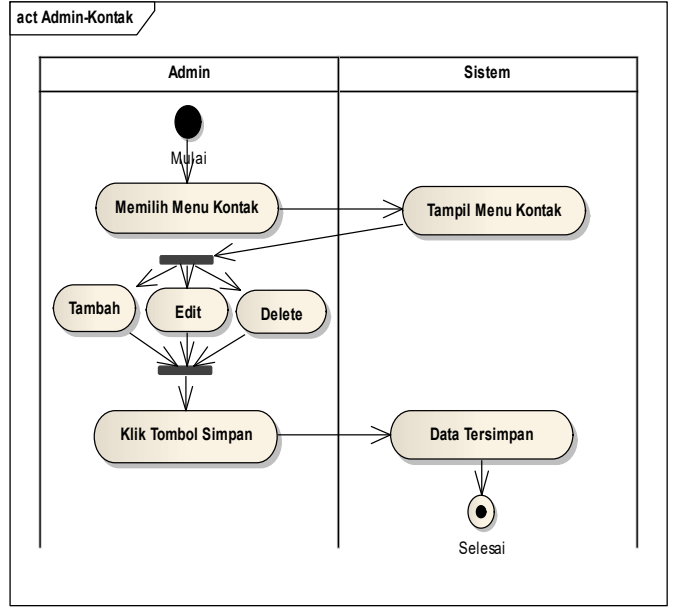

Gambar 6 Activity Diagram Halaman Kontak Admin

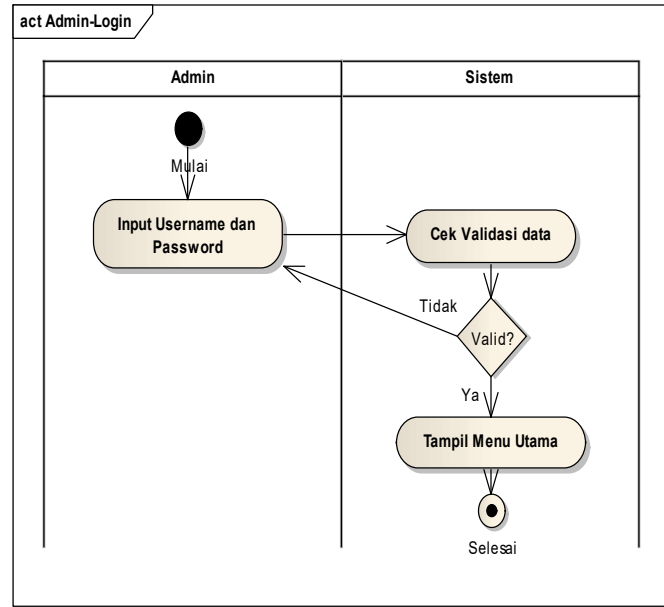

Gambar 7 Activity Diagram Halaman Login User

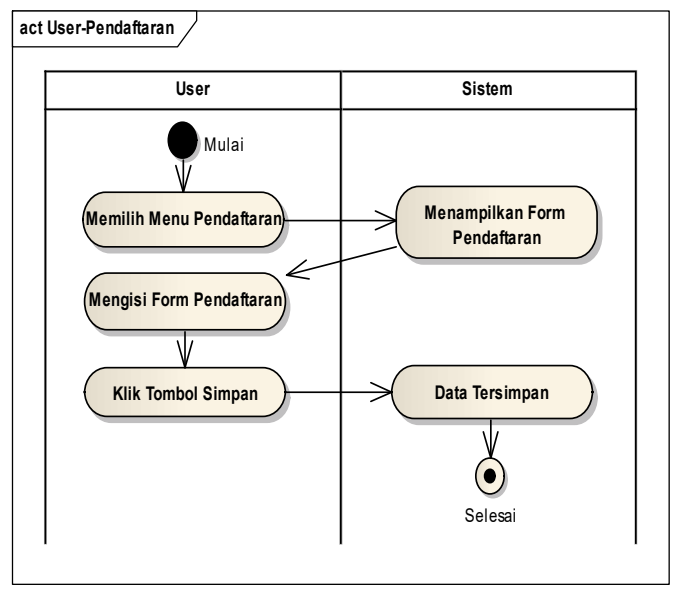

Gambar 8 Activity Diagram Halaman Pendaftaran User

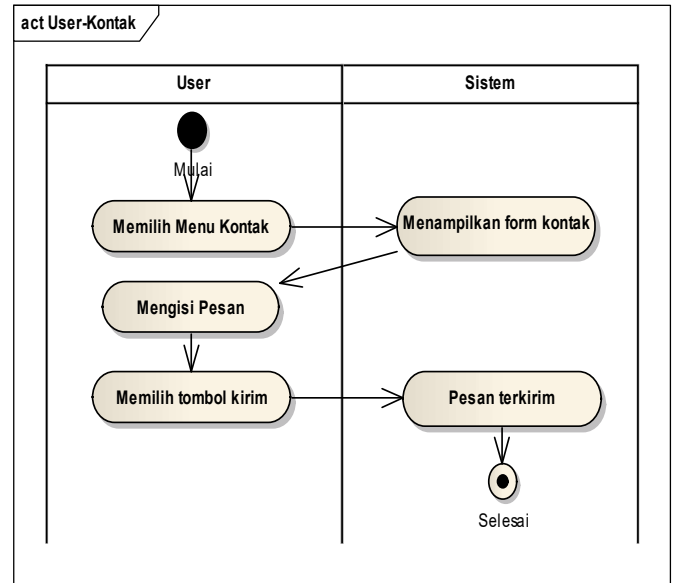

Gambar 9 Activity Diagram Halaman Kontak User

\subsection{Basis Data}

A. Entity Relationship Diagram (ERD)

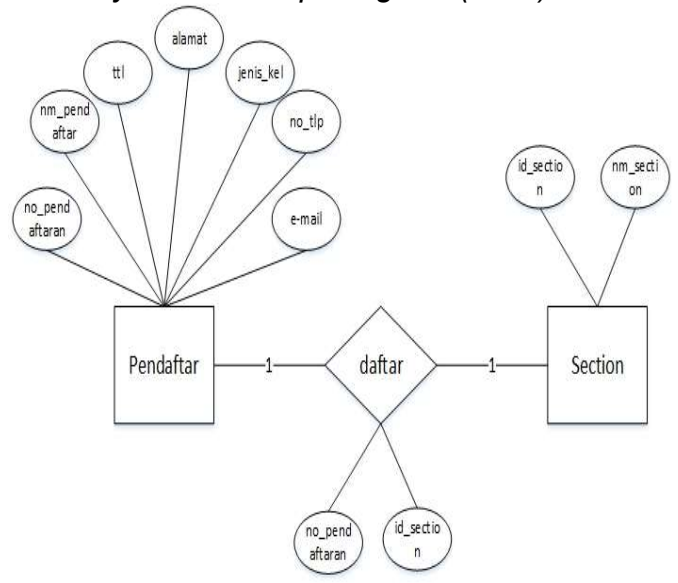

Gambar 10 Entity Relationship Diagram (ERD)

B. Logical Regional Structure (LRS)

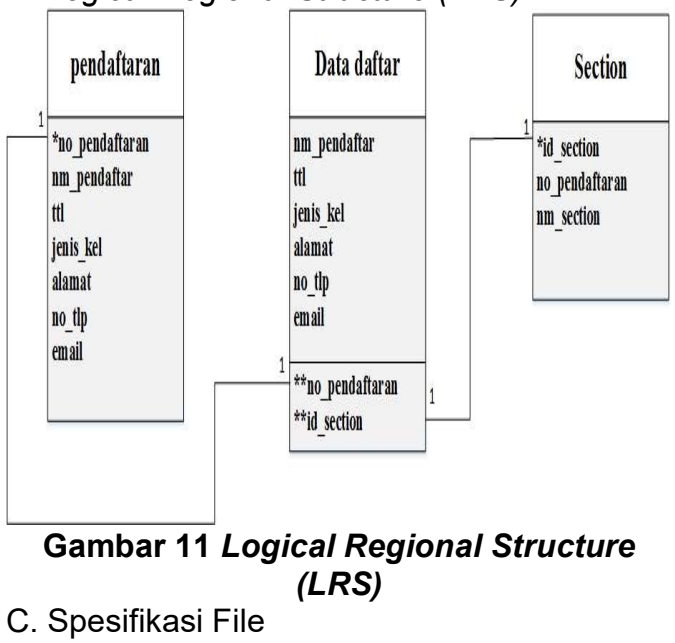


Spesifikasi file yang ada pada aplikasi pendaftaran anggota ini meliputi:

1. Spesifikasi File Pendaftaran

Nama File

Akronim

Fungsi

Tipe File

Organisasi File

Akses File

Media

Panjang Record

Kunci Field

Software
: Pendaftaran

: Pendaftaran

: Menyimpan data

pendaftaran

: File Transaksi

: Indexed Sequential

: Random

: Hard Disk

: 168 Karakter

: no_pendaftaran

: MySQL

Tabel 1

Spesifikasi File Pendaftaran

\begin{tabular}{|c|c|c|c|c|}
\hline No & Nama Field & Tipe & Size & Ket \\
\hline 1 & no_pendaftaran & int & 5 & PK \\
\hline 2 & nm_pendaftar & varchar & 35 & \\
\hline 3 & Tempat & varchar & 30 & \\
\hline 4 & tgl & date & & \\
\hline 5 & jenis_kel & varchar & 10 & \\
\hline 6 & alamat & varchar & 50 & \\
\hline 7 & no_telp & varchar & 13 & \\
\hline
\end{tabular}

2. Spesifikasi Section

$\begin{array}{ll}\text { Nama File } & \text { : Section } \\ \text { Akronim } & \text { : Section } \\ \text { Fungsi } & \begin{array}{l}\text { : Untuk menyimpan } \\ \text { data materi }\end{array} \\ & : \text { File Master } \\ \text { Tipe File } & \text { : Indexed Sequential } \\ \text { Organisasi File } & \text { : Random } \\ \text { Akses File } & \text { : Hard Disk } \\ \text { Media } & : \text { 110 Karakter } \\ \text { Panjang Record } & : \text { id_section } \\ \text { Kunci field } & \text { : MySQL } \\ \text { Software } & \end{array}$

Tabel 2

Spesifikasi File Section

\begin{tabular}{|c|c|c|c|}
\hline No & Nama Field & Type & Size \\
\hline 1 & id_section & int & 5 \\
\hline 2 & nm_section & varchar & 5 \\
\hline 3 & gambar & varchar & 100 \\
\hline 4 & keterangan & text & \\
\hline
\end{tabular}

3.3. Rancangan Stuktur Navigasi

A. Struktur Navigasi User

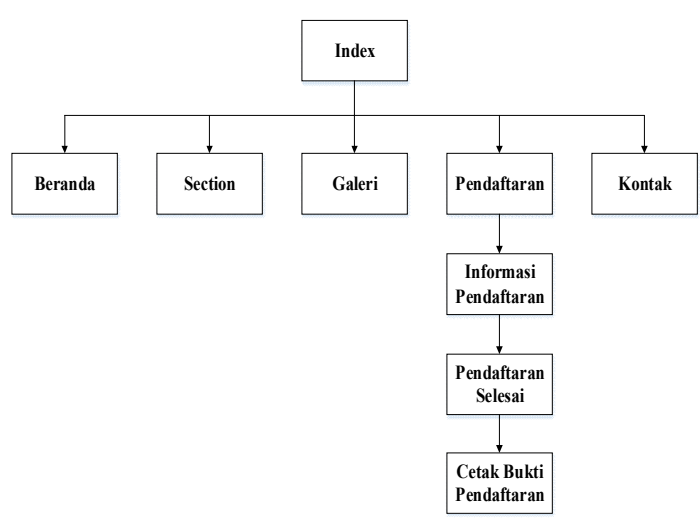

Gambar 12 Struktur Navigasi User

B. Struktur Navigasi Admin

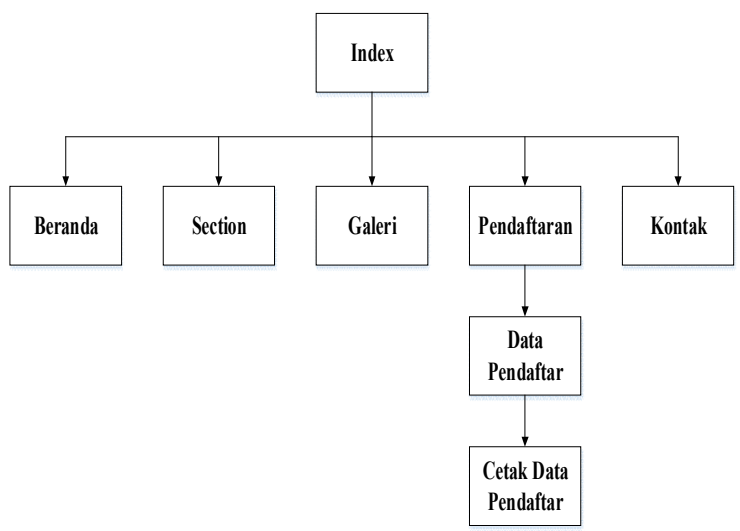

Gambar 13 Struktur Navigasi Admin

3.4. Rancangan Antar Muka

A. Rancangan Antar Muka Admin

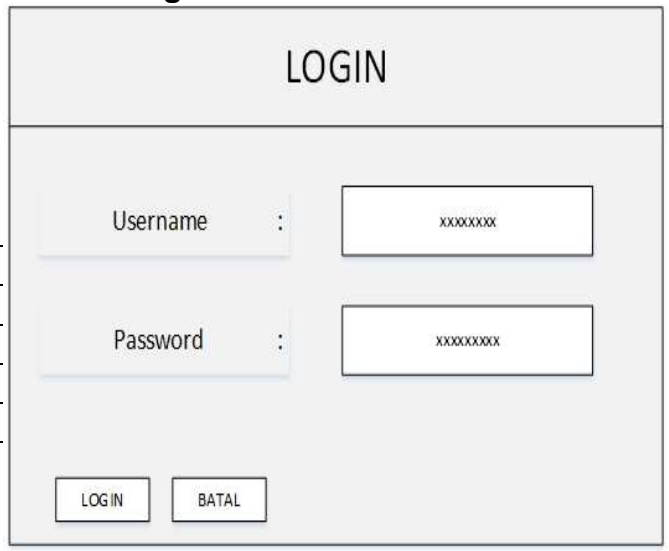

Gambar 14 Rancangan Antar Muka Admin

\section{B. Rancangan Antar Muka Admin \\ Pendaftaran}




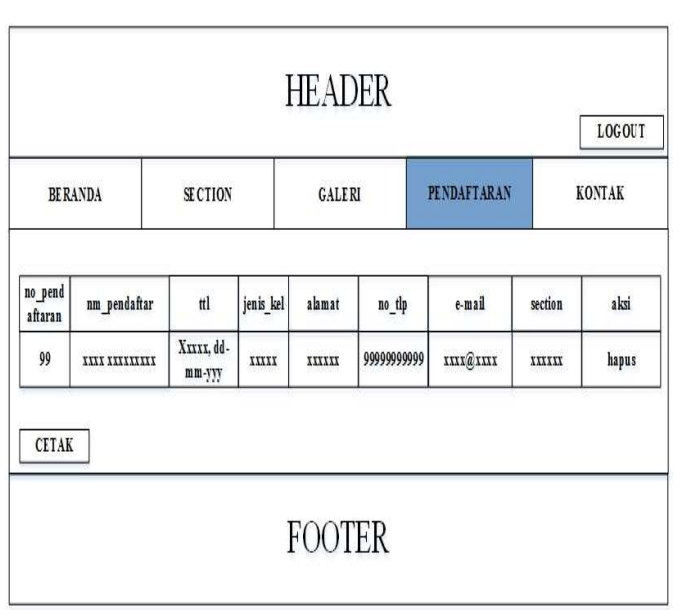

Gambar 15 Rancangan Antar Muka Admin Pendaftaran

C. Rancangan Antar Muka Admin Section

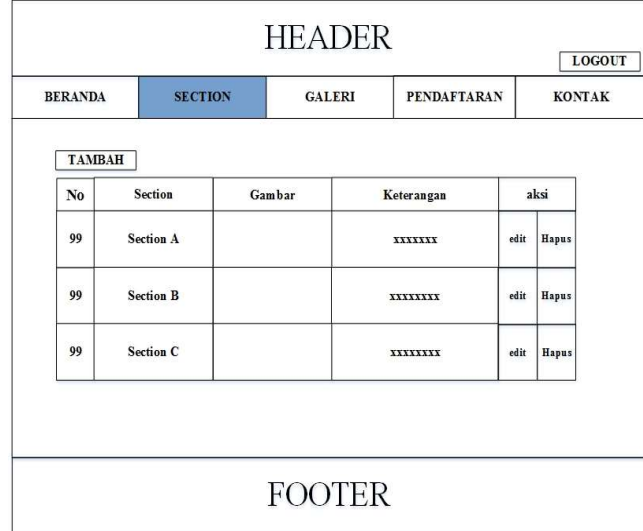

Gambar 16 Rancangan Antar Muka Admin Section

D. Rancangan Antar Muka Admin Beranda

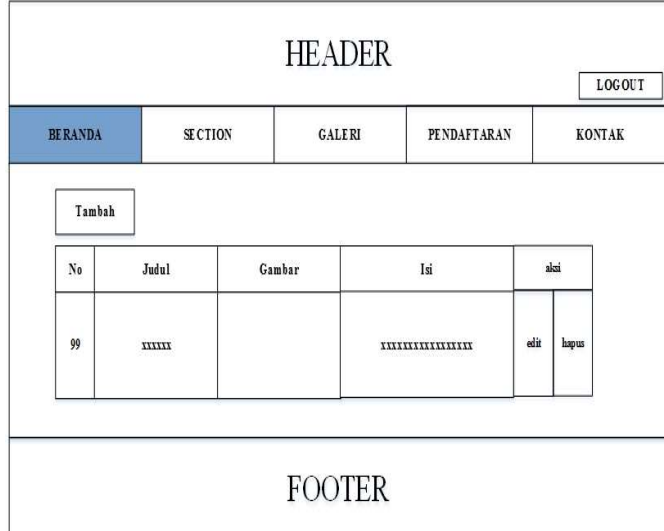

Gambar 17 Rancangan Antar Muka Admin Beranda

\section{E. Rancangan Antar Muka Admin Kontak}

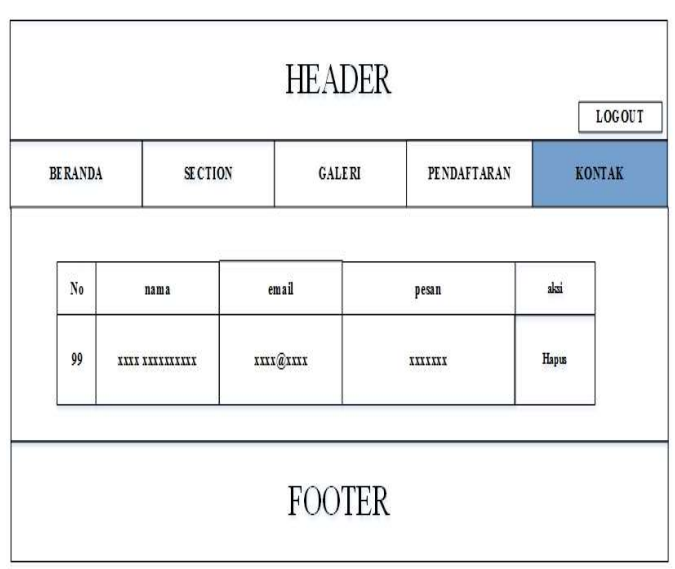

Gambar 18 Rancangan Antar Muka Admin Kontak

F. Rancangan Antar Muka User Pendaftaran

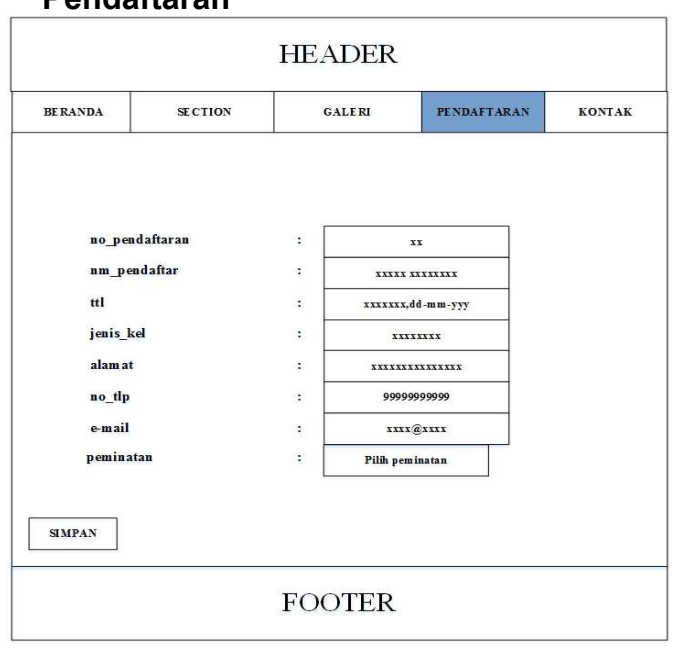

Gambar 19 Rancangan Antar Muka User Pendaftaran

\section{G. Rancangan Antar Muka User Peminatan}

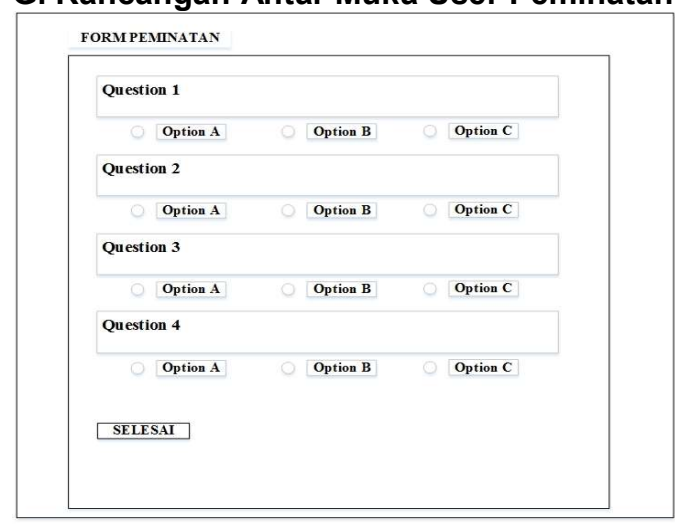

Gambar 20 Rancangan Antar Muka User Peminatan

H. Rancangan Antar Muka User Section 


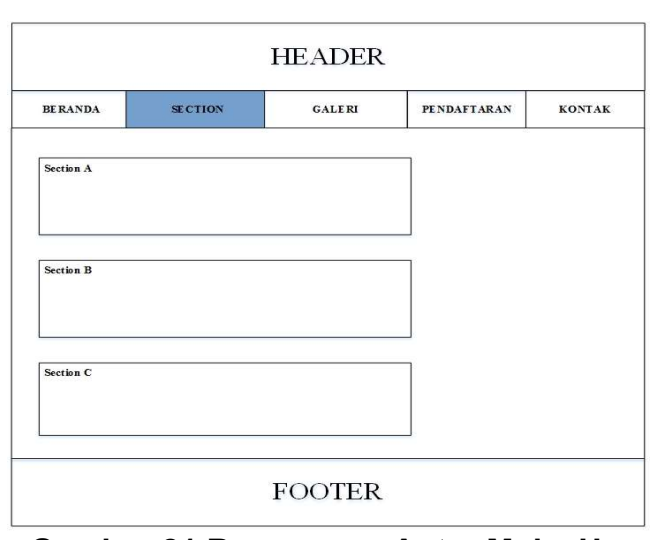

Gambar 21 Rancangan Antar Muka User Section

I. Rancangan Antar Muka User Beranda

\begin{tabular}{|c|c|c|c|c|}
\hline \multicolumn{5}{|c|}{ HEADER } \\
\hline BERANDA & section & GALER & PFNDAFTARAN & KONTAK \\
\hline \multicolumn{5}{|l|}{\begin{tabular}{|l|} 
Berital \\
\end{tabular}} \\
\hline \multicolumn{5}{|l|}{\begin{tabular}{|l|} 
Beritia22 \\
\end{tabular}} \\
\hline & & OTE & & \\
\hline
\end{tabular}

Gambar 22 Rancangan Antar Muka User Beranda

\section{J. Rancangan Antar Muka User Kontak}

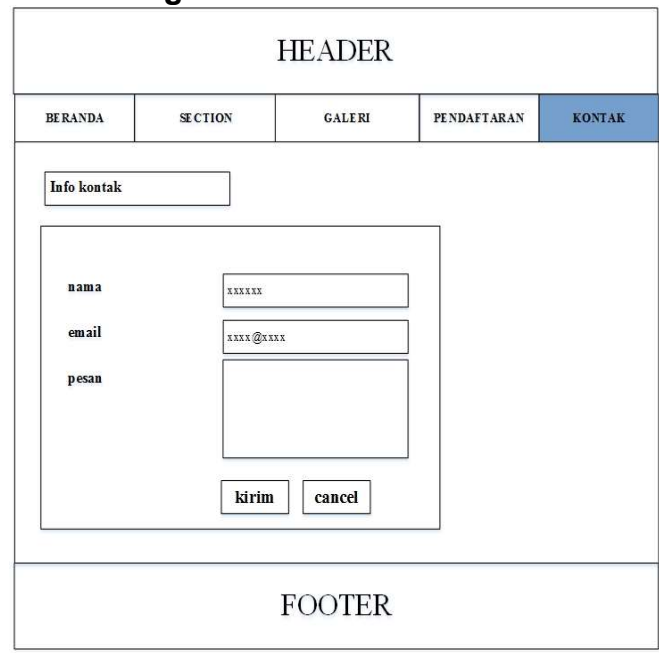

Gambar 23 Rancangan Antar Muka User Kontak
3.5. Implementasi

A. Rancangan Antar Muka Halaman Login Admin

LOGIN ADMIN

Username

1

Password

a.

Login Batal

Gambar 24 Rancangan Antar Muka Halaman Login Admin

B. Rancangan Antar Muka Halaman Admin Pendaftaran
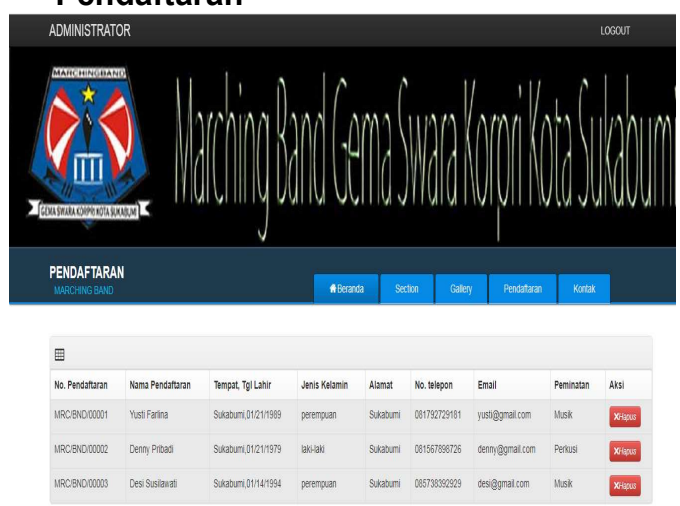

Gambar 25 Rancangan Antar Muka Halaman Admin Pendaftaran

C. Rancangan Antar Muka Halaman Admin Section

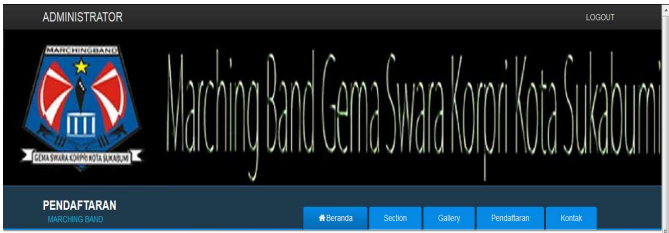

田

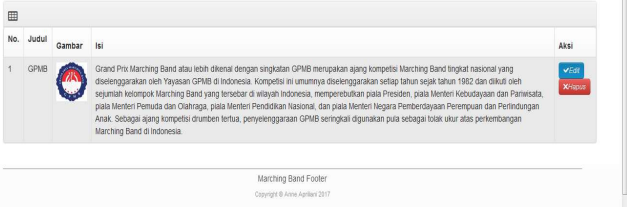

Gambar 26 Rancangan Antar Muka Halaman Admin Section

D. Rancangan Antar Muka Halaman Admin Beranda 


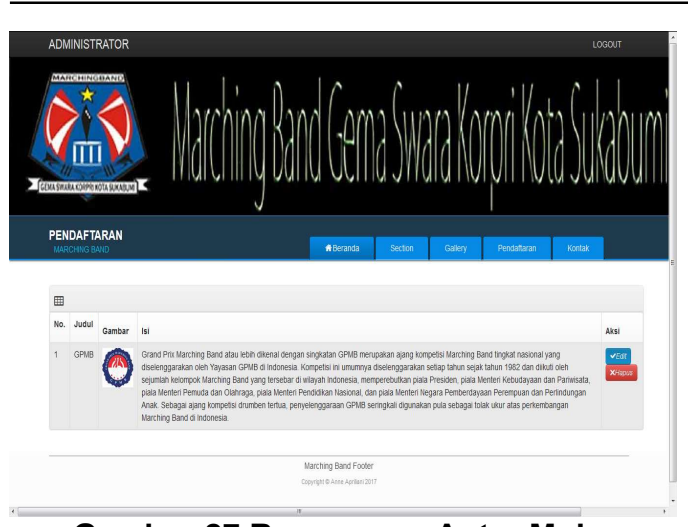

\section{Gambar 27 Rancangan Antar Muka} Halaman Admin Beranda

E. Rancangan Antar Muka Halaman Admin Kontak
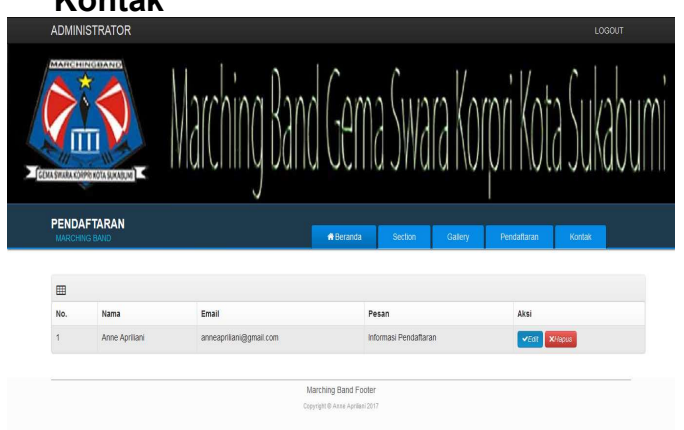

Gambar 28 Rancangan Antar Muka Halaman Admin Kontak

F. Rancangan Antar Muka Halaman User Pendaftaran

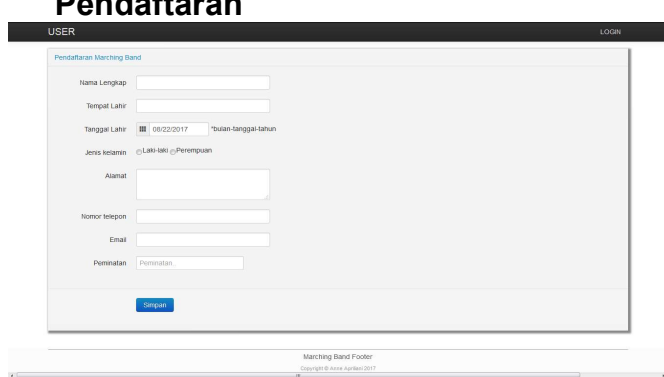

Gambar 29 Rancangan Antar Muka Halaman User Pendaftaran

G. Rancangan Antar Muka Halaman User Peminatan

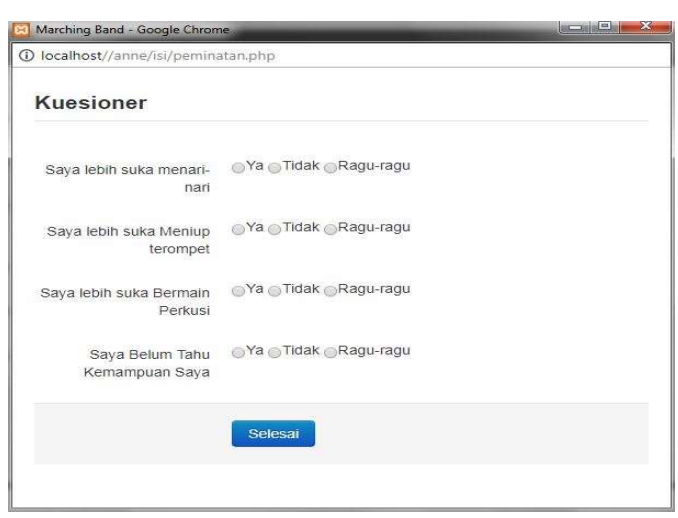

Gambar 30 Rancangan Antar Muka Halaman User Peminatan

H. Rancangan Antar Muka Halaman User Section

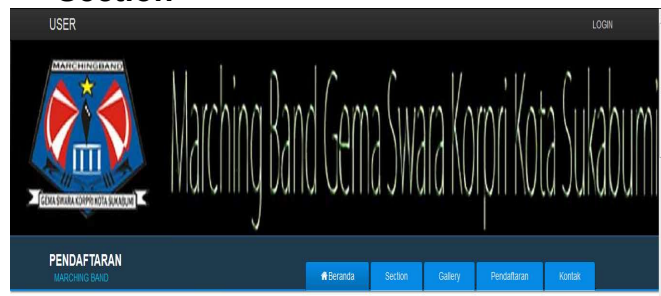

Brass

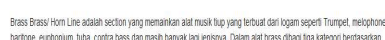

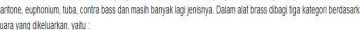

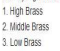

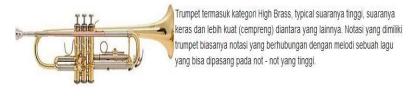

Gambar 31 Rancangan Antar Muka Halaman User Section

I. Rancangan Antar Muka Halaman User Beranda
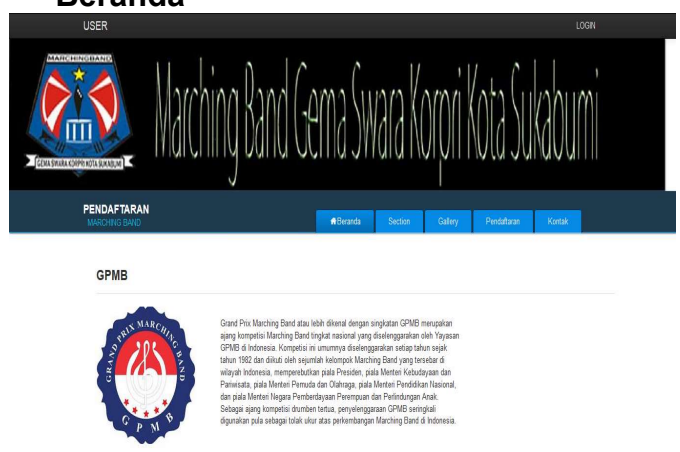

Gambar 32 Rancangan Antar Muka Halaman User Beranda

J. Rancangan Antar Muka Halaman User Kontak 


\section{PENDAFTARAN}
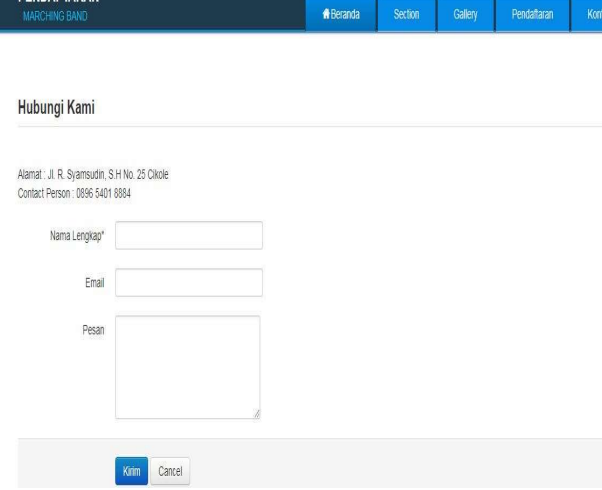

Gambar 33 Rancangan Antar Muka Halaman User Kontak

3.6. Pengujian Unit

a. Hasil Pengujian Black Box Testing Halaman Pendaftaran

Tabel 3

Hasil Pengujian Black Box Testing Halaman Pendaftaran

\begin{tabular}{|c|c|c|c|}
\hline $\begin{array}{l}\text { Skenario } \\
\text { Pengujian }\end{array}$ & $\begin{array}{l}\text { Test } \\
\text { Case }\end{array}$ & $\begin{array}{l}\text { Hasil yang } \\
\text { diharapkan }\end{array}$ & $\begin{array}{c}\text { Hasil } \\
\text { Pengujian }\end{array}$ \\
\hline $\begin{array}{l}\text { Mengosong } \\
\text { kan Biodata } \\
\text { calon } \\
\text { anggota } \\
\text { dan } \\
\text { Validasi } \\
\text { kemudian } \\
\text { klik Proses }\end{array}$ & $\begin{array}{l}\text { Biodata } \\
\text { calon } \\
\text { anggota: } \\
\text { (kosong) } \\
\text { Validasi: } \\
\text { (kosong) }\end{array}$ & $\begin{array}{l}\text { Sistem akan } \\
\text { menolak } \\
\text { untuk daftar } \\
\text { baru dan } \\
\text { menampilka } \\
\text { n masing- } \\
\text { masing data } \\
\text { harus diisi }\end{array}$ & $\begin{array}{c}\text { Sesuai } \\
\text { Harapan }\end{array}$ \\
\hline $\begin{array}{l}\text { Mengisi } \\
\text { Biodata } \\
\text { calon } \\
\text { anggota } \\
\text { dan Validasi } \\
\text { kemudian } \\
\text { klik Proses }\end{array}$ & $\begin{array}{l}\text { Biodata } \\
\text { calon } \\
\text { anggota: } \\
\text { (benar) } \\
\text { Validasi: } \\
\text { (benar) }\end{array}$ & $\begin{array}{l}\text { Sistem akan } \\
\text { menerima } \\
\text { pembuatan } \\
\text { daftar baru }\end{array}$ & $\begin{array}{l}\text { Sesuai } \\
\text { Harapan }\end{array}$ \\
\hline
\end{tabular}

b. Hasil Pengujian Black Box Testing Halaman Peminatan

Tabel 4

Hasil Pengujian Black Box Testing Halaman Peminatan

\begin{tabular}{|l|l|l|c|}
\hline $\begin{array}{l}\text { Skenario } \\
\text { Pengujian }\end{array}$ & Test Case & $\begin{array}{l}\text { Hasil yang } \\
\text { diharapkan }\end{array}$ & $\begin{array}{c}\text { Hasil } \\
\text { Pengujian }\end{array}$ \\
\hline $\begin{array}{l}\text { Mengoson } \\
\text { gkan opsi } \\
\text { jawaban } \\
\text { dan } \\
\text { Validasi }\end{array}$ & $\begin{array}{l}\text { Opsi } \\
\text { Jawaban: } \\
\text { (kosong) }\end{array}$ & $\begin{array}{l}\text { Sistem akan } \\
\text { menolak } \\
\text { untuk } \\
\text { menyimpan } \\
\text { dan }\end{array}$ & $\begin{array}{c}\text { Sesuai } \\
\text { Harapan }\end{array}$ \\
\hline
\end{tabular}

\begin{tabular}{|l|l|l|l|}
\hline $\begin{array}{l}\text { kemudian } \\
\text { klik Proses }\end{array}$ & $\begin{array}{l}\text { Validasi: } \\
\text { (kosong) }\end{array}$ & $\begin{array}{l}\text { menampilka } \\
\text { n masing- } \\
\text { masing data } \\
\text { harus diisi }\end{array}$ & \\
\hline $\begin{array}{l}\text { Mengisi } \\
\text { Opsi } \\
\text { Jawaban } \\
\text { dan } \\
\text { Validasi } \\
\text { kemudian } \\
\text { klik Proses }\end{array}$ & $\begin{array}{l}\text { Jawaban: } \\
\text { (benar) }\end{array}$ & $\begin{array}{l}\text { Sistem akan } \\
\text { menyimpan } \\
\text { datidasi: }\end{array}$ & $\begin{array}{c}\text { Sesuai } \\
\text { Harapan }\end{array}$ \\
\hline
\end{tabular}

4. Kesimpulan

Hasil dari uraian materi yang telah disampaikan pada bab-bab sebelumnya maka dapat ditarik kesimpulan sebagai berikut:

a. Dengan adanya website pendaftaran anggota baru pada Marching Band Gema Swara Kota Sukabumi (GSKS) dapat mempermudah dan mempercepat proses pendaftaran, juga dapat diakses darimana saja melalui media internet.

b. Memudahkan bagian admin dalam mengelola data anggota.

c. Mempermudah bagian admin dalam membuat laporan, sehingga lebih cepat dan tepat.

d. Memberikan dampak positif dalam hal media promosi agar lebih dikenal lagi oleh masyakarat luas.

e. Diharapakan untuk penelitian selanjutnya bisa dikembangkan dengan menambahkan laporan data anggota sehingga dapat diketahui mana anggota aktif dan anggota yang tidak aktif.

f. Diharapkan dapat menambahkan tes secara online dalam pengetahuan alat dasar yang digunakan pada marching band.

\section{Referensi}

Agusta, R., Lubis, E., \& Sudarman, Y. (2016). Pelaksanaan Kegiatan Ekstrakurikuler Marching Band Gita Abdi Praja Di IPDN Kampus Sumatera Barat. E-Jurnal Sendratasik FBS, 5(1), 38-43.

Aulia, S. A. N., Gusrayani, D., \& Julia. (2017). Kajian Pembelajaran Alat Musik Drum Band Di SDN Citengah Kabupaten Sumedang. Jurnal Pena IImiah, 2(1), 521-530.

Choliviana, E., \& Yulianto, L. (2013). Pembuatan Sistem Pendaftaran Anggota 
Secara Online Pada Organisasi Himpunan Mahasiswa Islam (Hmi) Kabupaten Pacitan. Journal Speed, 5(1), 53-60.

Dermawan, J., \& Hartini, S. (2017). Implementasi Model Waterfall Pada Pengembangan Sistem Informasi Perhitungan Nilai Mata Pelajaran Berbasis Web Pada Sekolah Dasar AlAzhar Syifa Budi Jatibening. Paradigma, 19(2), 142-147.

Farlina, Y., Hudin, J. M., Yulianti, I., \& Maulana, M. (2019). Rancang Bangun ECommerce Berbantuan SMS Gateway Pada Audrey Batik Sukabumi. Jurnal Swabumi, 7(1), 14-19.

Firmansyah, Y. (2018). Penerapan Metode SDLC Waterfall Dalam Pembuatan Sistem Informasi Akademik Berbasis Web Studi Kasus Pondok Pesantren AlHabi Sholeh Kabupaten Kubu Raya, Kalimantan Barat. Jurnal Teknologi \& Manajemen Informatika, 4(1), 184-191.

Pamungkas, I. (2014). Analisis Kesulitan Belajar Drum Band TK Pertiwi 31 Kelurahan Plalangan Kecamatan Gunungpati Kota Semarang. Jurnal Seni Musik, 3(1), 1-7.

Sasmito, G. W. (2017). Penerapan Metode Waterfall Pada Desain Sistem Informasi Geografis Industri Kabupaten Tegal. Jurnal Pengembangan IT (JPIT), 2(1), 6 12.

Tabrani, M., \& Pudjiarti, E. (2017). Penerapan Metode Waterfall Pada Sistem Informasi Inventori PT. Pangan Sehat Sejahtera. Jurnal Inkofar, 1(2), 30-40. 